\title{
CONHECIMENTOS, CONCEPÇÕES E PRÁTICAS DE PROFESSORES ACERCA DO PROCESSO DE ALFABETIZAÇÃO DA CRIANÇA COM DEFICIÊNCIA INTELECTUAL
}

\author{
KNOWLEDGE AND CONCEPTIONS OF TEACHERS ABOUT THE PROCESSOF LITERACY OF \\ CHILDREN WITH INTELLECTUAL DISABILITIES
}

Rose Mary Fraga Pereira Prefeitura Municipal de Vitória-ES rosemfraga@hotmail.com

Sonia Lopes Victor Universidade Federal do Espírito Santo sonialopesvictor@gmail.com

\section{RESUMO}

Objetiva-se analisar os conhecimentos e as concepções e as práticas de professores do Município de Vitória, Espírito Santo sobre o processo de alfabetização da criança com Deficiência Intelectual. Tratase de um estudo de natureza qualitativa do tipo exploratório, tendo Vigotski como principal interlocutor. Para tanto, foram realizadas entrevistas semiestruturadas. Os resultados produzidos evidenciam que o Município tem investido em formação para essas profissionais, todavia ainda parece incipiente essa formação ou necessita ser revista para atender as demandas da ação pedagógica, com vistas à garantia dos processos de alfabetização, principalmente, junto aos alunos público-alvo da educação especial com Deficiência Intelectual.

Palavras-chave: Alfabetização. Deficiência Intelectual. Ensino Fundamental. Abordagem históricocultural.

\begin{abstract}
The objective is to analyze the knowledge and conceptions and practices of teachers in the city of Vitória/ES about the literacy process of children with Intellectual Disabilities (ID). This is a qualitative study of the exploratory type, with Vigotski the main interlocutors. For this purpose, semi-structured interviews were carried out. The results indicate that the Municipality has invested in training for these professionals, however, this training still seems incipient or needs to be reviewed to meet the demands of pedagogical action, with a view to guaranteeing literacy processes, especially with s target-audience students of special Education with Intellectual Disabilities.
\end{abstract}

Keywords: Literacy. Intellectual Disability. Elementary School. Historical-cultural approach. 


\section{Introdução}

O estudo é uma investigação realizada em nível de doutoramento que visou analisar os conhecimentos e as concepções de professores do Município de Vitória (ES) sobre o processo de alfabetização da criança com Deficiência Intelectual. Destarte, serão evidenciados dados coletados no âmbito da pesquisa, especificamente aqueles produzidos a partir da aplicação de uma entrevista semiestruturada a professores que trabalham no primeiro ano do Ensino Fundamental do sistema público de ensino sobre os conhecimentos, concepções e as práticas dos professores sobre o processo de alfabetização da criança com DI do primeiro ano do Ensino Fundamental.

No processo de pesquisa, utilizamos também a categoria "formação" que perpassa e problematiza com mais profundidade os conhecimentos, concepções e práticas das professoras alfabetizadoras.

Nesse contexto, a tese observa se o processo de alfabetização é considerado sob a perspectiva de teorias que concebem a aprendizagem e o desenvolvimento infantil de forma não linear e não previsível, a fim de procurar caminhos alternativos e apoios/recursos apropriados que possam contribuir para o processo de alfabetização da criança com DI, como a abordagem histórico-cultural, sendo possível a garantia de seu direito à educação não apenas no que se refere à sua socialização na escola comum, mas também à sua aprendizagem.

A alfabetização representa um importante problema de política pública (OLIVEIRA, 2008). Não a esmo, frente aos dados nacionais de desempenho em leitura e escrita das crianças brasileiras, a alfabetização é um problema existente. As questões sobre a alfabetização são centrais quando discutimos os processos de inclusão na escola, considerando-os também um problema de política pública, revelada no desejo de constituição de uma escola para todos. É preciso investimento na educação, na formação dos professores, em políticas públicas, entre outros aspectos que devem ser repensados. Coube, portanto, a esta pesquisa debater temas complexos que envolvem inclusão escolar, alfabetização e DI, articulando-os entre si.

Não se pode pensar nesse convívio com as diferenças sem levar em consideração que a questão da igualdade se relaciona às diversas formas de manifestação e reivindicação pelo direito do aluno público-alvo da educação especial ao processo de leitura e escrita. Dessa forma, a educação inclusiva está posta como uma missão ético-política que se compromete em asseverar ao sujeito que ele tem direito à educação "[...] pela via de democratização e da universalização do acesso às escolas com qualidade de ensino, capazes de assegurar o desenvolvimento das possibilidades dos alunos" (PRIETO et al., 2008, p. 16).

Entretanto, pode-se perceber, nas considerações de muitos autores nacionais sobre essa temática, como Gontijo (2008), que, diariamente, há notícias, veiculadas pela mídia e pelos jornais do Brasil, que denunciam os níveis baixos de aprendizagem da linguagem escrita. Ademais, crianças, adolescentes, jovens e adultos chegam às séries finais do Ensino Fundamental e ao Ensino Médio com muitos problemas no domínio da leitura e da escrita (PINTO et al., 2015).

Além dessas considerações gerais sobre a questão da alfabetização na perspectiva da educação inclusiva, vinculada à questão sobre o direito à educação, acredita-se, ainda com base nas considerações de Gontijo (2014), que as pesquisas com objetivo de proposição de estágios de desenvolvimento da leitura e escrita na criança não contribuem muito para a solução dos problemas encontrados pelos aprendizes. Contrário a isso, têm servido, diversas vezes, para o estabelecimento de padrões de comportamento e de desenvolvimento infantil que atuam de forma perversa sobre as crianças que apresentam padrões diferentes dos estabelecidos ou que não conseguem 
progredir para estágios mais avançados desse desenvolvimento. Esse modo de compreender o desenvolvimento da criança para o aprendizado da leitura e escrita no processo de alfabetização dificulta percebê-lo, consoante Vigotski, como parte do desenvolvimento que se caracteriza por um processo dialético:

[...] um processo dialético complexo caracterizado por uma frequência múltipla, por um desequilíbrio no desenvolvimento de diferentes funções, transformações ou mudanças qualitativas de uma forma distinta, o complexo entrecruzamento dos processos de evolução e involução, a reação entre os fatores internos e externos e o intricado processo de superar as dificuldades e a adaptação (VIGOTSKI, 1987, p. 151, tradução nossa).

Verifica-se a necessidade de teorias que revelem essa multiplicidade de acontecimentos no desenvolvimento durante os processos de aprendizagem da criança e que não os concebam dentro de uma perspectiva linear e previsível, reforçando a ideia de normalização e a necessidade de adaptação do aluno com DI às condições sociais pré-estabelecidas. Para tanto, conforme Góes (2008, p. 37), "[...] a abordagem histórico-cultural tem lugar privilegiado no cenário das contribuições a esse respeito [...]". Além disso, ao tratar sobre esse assunto no contexto da educação inclusiva, a referida abordagem permite "[...] uma compreensão muito consistente da interdependência dos termos referidos - possibilidades e responsabilidade".

Desse modo, refletir sobre alfabetização da criança com DI com base na abordagem histórico-cultural, no contexto da perspectiva da educação inclusiva, é também lidar com as questões próprias dessa perspectiva, a qual tem se configurado como um processo complexo, pois o trabalho pedagógico a ser desempenhado exige formação dos professores tanto da sala de ensino comum quanto para o Atendimento Educacional Especializado (AEE), que acontece na Sala de Recursos Multifuncionais (SRM), para conhecer as especificidades necessárias à organização dos processos de alfabetização dessa criança. Tal processo de alfabetização requer uma série de estratégias sistemáticas, planejadas e avaliadas que contemplem suas demandas (SILVA; ARRUDA, 2014). Logo, torna-se essencial a sustentação de consistentes processos de formação inicial e continuada, a fim de atribuir indissociabilidade entre teoria e prática junto aos professores, sendo a crítica reflexiva uma condição inerente à transformação das práticas educacionais, "[...] permanecendo, assim, vivas a aposta no diálogo e a busca de conhecimentos" (JESUS, 2009, p. 6).

O progresso do número de matrículas de crianças com DI na escola regular, ultimamente, tem provocado debates a respeito de como vêm sendo atendidos esses alunos no ensino regular, quando o processo de alfabetização da criança de seis anos com DI ocorre na escola comum. Essas são as interrogações presentes nas escolas e nos programas de pós-graduação. Tal discussão é importante na esfera acadêmica, visto que ainda não foram obtidas muitas respostas acerca da escolarização desses alunos no ensino comum, conforme pesquisas de Veltrone e Mendes (2007). No entanto, a experiência no espaço escolar é essencial para o desenvolvimento da criança com DI, considerando que é o ambiente para estabelecer-se relações e ações potencializadoras para a aprendizagem dos conhecimentos historicamente acumulados pela humanidade nos diferentes contextos socioculturais. Essa temática é de interesse e faz parte da vivência de alguns dos profissionais da escola, que se indagam criticamente a respeito de como vêm sendo atendidos esses alunos no ensino regular, quando o processo de alfabetização da criança de seis anos com DI ocorre na escola comum. 


\section{A política de alfabetização no Município de Vitória}

Neste município, as três dimensões que integram a política de Alfabetização delineada no documento Política de Alfabetização em Vitória para o Ciclo Inicial de Aprendizagem são: "a inserção das crianças de seis anos de idade no Ensino Fundamental de nove anos; a organização do Ciclo Inicial de Aprendizagem e o processo de alfabetização" (VITÓRIA, 2012, p. 31).

O Ministério da Educação e Cultura (MEC), por meio do Parecer do Conselho Nacional de Educação (CNE) n 4, de 20 de fevereiro de 2008, propõe assim que os três primeiros anos, dos nove anos que compõem o Ensino Fundamental, sejam organizados em Ciclos, denominados "ciclo da infância". Ademais é uma política educativa que

[...] objetiva respeitar as experiências, bem como a temporalidade necessária para que cada criança desenvolva seu potencial em suas diferentes formas de aprender, considerando relações sociais e aspectos culturais e, visando romper com a concepção de "currículo conteudista". Esta política busca garantir uma proposta curricular que transforma a escola num tempo-espaço de socialização e produção de saberes, da qual as crianças têm o direito de se apropriarem (VITÓRIA, 2011, p. 11).

Nesse contexto, tornou-se necessária a organização de um documento que expusesse os princípios básicos do ciclo implementado no Sistema Municipal de Educação de Vitória.

A concepção de ciclo que esta secretaria defende e, nesse sentido, considerando que ele se remete ao ciclo inicial dos anos iniciais do ensino fundamental $-1^{\circ}, 2^{\circ}$ e $3^{\circ}$ anos ${ }^{1}$, também se destacam as questões referentes ao processo de alfabetização e, assim, questões sobre o processo de organização do trabalho pedagógico: de ensino, de aprendizagem, de conhecimento, de avaliação, de planejamento, de interdisciplinaridade, dentre outros (VITÓRIA, 2012, p. 32).

Desse modo, levando em consideração as possibilidades indicadas pelo Ministério da Educação (MEC) e pelo Conselho Municipal de Educação (COMEV), a Secretaria Municipal de Educação (SEME) ressalta, por meio do documento orientador, "[...] o Ciclo Inicial de Aprendizagem como uma prioridade estratégica para que se efetive a real melhoria na qualidade do ensino-aprendizagem da alfabetização" (VITÓRIA, 2011, p. 10).

Outrossim, essa meta é importante, uma vez que vislumbra a relevância de se assegurar uma educação de qualidade para todas as crianças, tornando-a democrática, com possibilidade de revisão dos tempos e espaços de ensino-aprendizagem, como também abre caminhos para que todas as crianças consigam se apropriar, aprofundar e consolidar "[...] os conhecimentos trabalhados no processo de alfabetização em três anos, com vistas à formação de sujeitos críticos, leitores e produtores de textos" (VITÓRIA, 2012, p. 32).

\footnotetext{
1 "[...] Segundo a Base Nacional Comum Curricular (BNCC) o processo de alfabetização, que atualmente é feito até o $3^{\circ}$ ano do Ensino Fundamental, deverá ser antecipado para o $2^{\circ}$ ano do Ensino Fundamental, quando as crianças geralmente têm 7 anos. [...]" (PROPOSTA..., 2017).
} 


\section{Caminhos teórico-metodológicos da abordagem histórico-cultural e o processo de apropriação da escrita}

A abordagem histórico-cultural constitui o aporte teórico desta pesquisa, especificamente os estudos de Vigotski que contribuem no entendimento da constituição da aprendizagem, tendo como foco de investigação conhecimentos e concepções de professores alfabetizadores da criança com DI do primeiro ano do Ensino Fundamental. A abordagem histórico-cultural fornece uma concepção de sujeito para além das visões que se concentram na limitação e na incapacidade provocada pela deficiência. Vigotski (1987) propõe outra forma de pensar a aprendizagem e o desenvolvimento desses sujeitos, concentrada nas possibilidades que as diferentes situações de interação social podem favorecer. Desloca o seu olhar para a importância das relações sociais no desenvolvimento do sujeito, em detrimento de visões que retratam a limitação como algo inato às suas próprias condições individuais e internas (VIGOTSKI, 1987).

Para Vigotski, a formação da consciência e o desenvolvimento cognitivo ocorrem do plano social para o individual, seguindo um processo de apropriação, não de forma mecânica, mas impregnada pela ação do sujeito. Esse processo de apropriação possibilita a construção do conhecimento e da cultura e envolve uma atividade mental perpassada pelo domínio de instrumentos de mediação do ser humano com o mundo. Entre essas ferramentas, encontra-se a linguagem. Para o autor, "[...] o pensamento e a linguagem são a chave para a construção da natureza da consciência humana" (VYGOTSKI, 2000, p. 485). O autor destaca que a cultura reelabora as funções psicológicas estritamente humanas, modificando a estrutura psíquica.

[...] agora o educador começa a compreender que, com a inserção na cultura, a criança não só adquire algo da cultura, assimila algo, algo do exterior e cria raízes nele, senão que também a própria cultura reelabora todo o comportamento natural da criança e refaz de uma nova forma o percurso do desenvolvimento (VYGOTSKY, 1997, p. 184, tradução nossa).

Libâneo e Freitas (2006) alertam para a necessidade de se verificar as formas de recepção da abordagem histórico-cultural no Brasil, uma vez que eles percebem o uso de várias teorias nas escolas, entre as quais, segundo os autores, se destacam Piaget, Pestalozzi e a pedagogia tradicional:

[...] embora a teoria histórico-cultural tenha influenciado o trabalho dos professores, pode-se dizer que isso vem ocorrendo de forma aprofundada e mesclada com pressupostos piagetianos [...] muito provavelmente os professores do ensino fundamental que utilizam metodologias inspiradas em Piaget, o façam com as lentes de Pestalozzi e até mesmo com as lentes da pedagogia tradicional" (LIBÂNEO; FREITAS, 2006 p. 6-7).

Essa mescla pode ter sido ocasionada também devido às primeiras traduções das obras de Vigotski que teriam sofrido modificações em seu texto original (LIBÂNEO; FREITAS, 2006). Apesar disso, podemos visualizar algumas orientações pedagógicas inseridas no campo da educação, tais como:

[...] o papel ativo dos sujeitos na aprendizagem escolar, a construção de conceitos a partir das representações dos alunos, a relação entre o conhecimento e a realidade, a formação de valores por meio do currículo, a criação de situações de interação e cooperação entre os alunos (LIBÂNEO; FREITAS, 2006, p. 7). 
Assim, podemos ainda observar a permanência da escrita mecânica. A escrita possui estreita ligação com o desenvolvimento cultural infantil, entretanto não se privilegia a linguagem escrita, nessa relação cultural, ensinando-se às crianças a desenhar letras e a construir palavras com elas. Logo, acentua-se a mecânica de ler o que está escrito, o que acaba tornando pouco visível a linguagem escrita como tal (VIGOTSKI, 2003). Justifica-se essa situação a partir de fatores históricos de forma específica, como criticado por Vigotski, dado o fato de que a pedagogia prática, apesar de existirem vários métodos de ensinar a ler e escrever, não priorizava o desenvolvimento de um procedimento científico real para o ensino da linguagem escrita às crianças. De modo diferente do ensino da linguagem falada, em que a criança pode se desenvolver por si própria, o ensino da linguagem escrita está ligado, diretamente, a um treinamento artificial (VIGOTSKI, 2003). A leitura e a escrita devem ser algo de que a criança precise, absolutamente, e devem provocar nela um sentido social como algo necessário e importante para a vida. O processo deixará de ser um hábito de mão e dedos e constituirá um modo novo e complexo de linguagem.

\section{Procedimentos para a realização do estudo}

A investigação configura-se como um estudo exploratório qualitativo, não tem a pretensão de generalizar, mas de proporcionar maior familiaridade com o problema, com vistas a torná-lo explícito e construir hipóteses (GIL, 2008, p. 27).

Para responder aos objetivos da pesquisa, entrevistamos no ano de 2016 quinze professoras alfabetizadoras $^{2}$ de alunos público-alvo da educação especial com DI de primeiro ano de dez Escolas Municipais de Ensino Fundamental (EMEF) e de dois Centros Municipais de Educação Infantil (CMEI) da Rede Municipal de Vitória/ES. Esses dados resultam também das anotações em diário de campo, feitas durante as entrevistas, e dos dados disponibilizados pela Secretaria Municipal de Educação (SEME) de Vitória. A partir dos dados da Educação Especial, identificamos sete regiões administrativas que tinham crianças com DI matriculadas no primeiro ano do Ensino Fundamental.

Para a produção de dados, selecionamos os seguintes instrumentos de pesquisa: 1) a análise documental; 2) a entrevista semiestruturada; 3) o diário de campo. Todos os dados produzidos foram registrados em gravações de áudio e anotações em diário de campo, durante a entrevista e, posteriormente, transcritos.

Organizamos um roteiro para a entrevista com questões que focalizassem o desenvolvimento do trabalho e o processo formativo, com perguntas disparadoras que incentivassem respostas mais elaboradas, menos objetivas, seguindo um roteiro específico relacionado com os objetivos propostos para o estudo e com a revisão de literatura. Para tanto, elaboramos as questões das entrevistas em três principais eixos: conhecimentos, concepções e práticas.

Ademais, embora vamos trabalhar com os eixos separadamente, eles não estão desconectados, visto que encontramos elementos de um no outro, uma vez que o nosso estudo está atrelado a aspectos histórico-culturais do sujeito, proporcionando, assim, o entrelaçamento de eixos trabalhados na pesquisa durante a análise de dados.

2 A partir do momento que conseguimos o contato com as instituições para a produção dos dados, elaboramos uma autorização para o desenvolvimento do trabalho com profissionais de instituição de Ensino Fundamental da rede municipal de ensino de Vitória/ES. O documento com a proposição da pesquisa e a importância de sua participação no processo do estudo, a ser assinado pelo participante, foi assinado pelo diretor da unidade de ensino, como também o Termo de Consentimento Livre e Esclarecido para as 15 professoras alfabetizadoras. 
Durante as entrevistas, percebemos que os conhecimentos das professoras alfabetizadoras interferem diretamente na organização e na intencionalidade da sua prática pedagógica. Por isso, temos a compreensão de que o eixo "conhecimentos" torna-se essencial para a nossa análise, pois considera questões teóricas importantes para atuação e sustentação da ação do professor no contexto do Ensino Fundamental. Os conhecimentos retratam sobre quais bases o trabalho docente tem se desenvolvido.

O eixo "concepções" colabora no sentido de exprimir, a partir dos conhecimentos e vivências, como têm sido elaborados os conceitos que, de acordo com a nossa visão, são fundamentais para o entendimento ideológico que ampara as práticas desenvolvidas com as crianças que apresentam deficiência.

Assim, a partir dos relatos das professoras, enumeramos dois eixos principais para essa discussão: a análise das concepções a respeito do conceito de alfabetização e a análise das concepções em relação ao processo de alfabetização, considerado sob a perspectiva histórico-cultural. Desse modo, em nosso roteiro elaboramos uma pergunta fundamental, a fim de que pudéssemos atingir o objetivo de saber qual a concepção do professor em relação ao processo histórico-cultural: "qual é a sua concepção sobre o processo de alfabetização?"

A discussão sobre as ações pedagógicas das professoras alfabetizadoras está diretamente relacionada aos dados produzidos durante as entrevistas. Nos relatos, as professoras alfabetizadoras revelaram temáticas importantes para o desenvolvimento infantil, como a brincadeira, as concepções de infância, a alfabetização, a aprendizagem e o desenvolvimento das crianças de seis anos. Além disso, o trabalho da alfabetização foi relacionado algumas vezes com as práticas realizadas na Educação Infantil.

O eixo a respeito de "o processo de alfabetização da criança público-alvo da educação especial: o que dizem as professoras alfabetizadoras?" aflora a partir do momento que percebemos como as professoras entendem a alfabetização da criança que apresenta DI, como uma prática limitada, difícil e que requer muitos estudos. Portanto, nesse momento, discutimos o trabalho realizado na sala de aula comum com a criança com Deficiência Intelectual, a organização desse trabalho, os entraves e as possibilidades de aprendizagem construídas nesse espaço.

Utilizamos também a categoria "formação" que perpassa e problematiza com mais profundidade os eixos já mostrados e que demanda um aprofundamento maior, passando a ser considerada uma categoria. Ela surgiu a partir da organização das nossas questões levantadas junto às participantes.

Desse modo, temos condições de avaliar se o processo de alfabetização é considerado sob a perspectiva de teorias que concebam a aprendizagem e o desenvolvimento infantil de forma não linear e não previsível, objetivando procurar caminhos alternativos e apoios/recursos apropriados que possam colaborar no processo de alfabetização da criança com Deficiência Intelectual como a abordagem histórico-cultural, seja possível a garantia de seu direito à educação não somente no que se refere à sua socialização na escola comum mas a sua aprendizagem.

\section{Organização e discussão dos dados}

Realizamos a análise dos dados produzidos por meio das entrevistas semiestruturadas, realizadas com as alfabetizadoras que trabalham em instituições de Ensino Fundamental com crianças que apresentam DI. Esses dados que resultaram também das anotações em diário de campo, feitas durante as entrevistas, e dos dados disponibilizados pela SEME de Vitória. 
Para tanto, destacamos quatro eixos temáticos que expressam as análises, a saber: conhecimentos de professoras alfabetizadoras de crianças de Ensino Fundamental de primeiro ano; concepções das professoras alfabetizadoras de alunos de primeiro ano; práticas pedagógicas das professoras alfabetizadoras: uma análise do processo de alfabetização na sala de aula regular; o processo de alfabetização da criança público-alvo da educação especial: o que dizem as professoras alfabetizadoras?

Utilizamos também a categoria "formação" que perpassa e problematiza com mais profundidade os eixos já mostrados e que demanda um aprofundamento maior, passando a ser considerada uma categoria. Ela surgiu a partir da organização das nossas questões levantadas junto às participantes.

\section{Conhecimentos de professoras alfabetizadoras de crianças de seis anos do ensino fundamental de primeiro ano}

Os conhecimentos das professoras alfabetizadoras de crianças de seis anos de idade, matriculadas no primeiro ano do ensino fundamental, tornam-se materiais essenciais para a nossa análise, pois consideram questões teóricas importantes para atuação e sustentação da ação do professor no contexto do Ensino Fundamental. De modo específico, os conhecimentos retratam sobre quais bases o trabalho docente tem se desenvolvido.

Percebemos que, das quinze docentes entrevistadas, onze fizeram a formação inicial em Pedagogia, sendo uma professora em Magistério e Pedagogia, outra em Magistério e Letras, uma outra em Magistério e História, outra em Magistério e Artes Visuais e, por fim, uma professora que fez o curso de Pedagogia e iniciou o curso de Ciências Sociais, sem conclúi-lo. A maioria possui curso de pós-graduação nas áreas de Educação, Educação Especial e Psicopedagogia e todas atuam na sala de ensino regular do primeiro ano de Ensino Fundamental com crianças de seis anos com DI. Muitas disseram que se envolvem em formação continuada, ofertada pelo Município de Vitória, em horário de trabalho, o que as motiva a participar. Ademais, a maioria delas destacou o processo de formação essencial para o seu trabalho.

A discussão dos processos formativos dos professores é pertinente para pensarmos o processo de inclusão no primeiro ano do Ensino Fundamental. Sob esse aspecto, estamos perfeitamente conscientes de que existe a necessidade de reavaliar o problema, reformular alguns itens na formação inicial dos professores, uma vez que os alunos com deficiências chegam às nossas escolas permanentemente $e$ muitos professores não sabem o que fazer com eles (GLAT; SANTOS; SOUSA; XAVIER, 2006). Esse dado também apareceu durante a entrevista, como uma lacuna na formação das professoras:

Na minha graduação vi um pouco da educação especial, mas vim enriquecer mais na minha Pós, [referindo-se à psicopedagogia], o que dificulta é que a escola não está adaptada para a criança de seis anos quanto mais para as crianças especiais também, a escola não tem nenhuma adaptação, assim, para a criança de seis anos quanto mais para as crianças especiais, né, não é nem questão de direção é questão muito maior, é questão de secretaria e tudo mais, aí a gente fica se esbarrando de como eu vou lidar com essa criança, a sala cheia, apesar de que hoje eu estou com 20 alunos, é uma sala pequena ainda, no CMEI você tem os cantinhos, essas escolas por ser pequena não oferece muita coisa assim, e a gente busca muito, a professora da educação especial é uma professora esforçada, a gente busca, mas ainda é elementar porque se você for comparar com as 'escolas especialistas' tem muito mais coisa lógica, não é sempre que a gente consegue tudo para trabalhar. É até mesmo questão da formação, porque são 'enes' (referindo-se a ideia de quantidade) deficiências para a gente se aprofundar nelas para saber lidar com tudo e a gente vai aprendendo, (PROFESSORA LARISSA. TRANSCRIÇÃO DA ENTREVISTA). 
Larissa parece entender que o processo de desenvolvimento das crianças com DI se diferencia das outras crianças, contudo, de acordo com a abordagem histórico-cultural, esse processo está sob as mesmas leis do desenvolvimento para as demais crianças. Os aspectos secundários são os que de fato limitam essa inserção cultural. Essa discussão vai ao encontro do que manifesta a professora Larissa quanto às condições concretas da escola de impossibilitar a aprendizagem desse alunado. Para tanto, o trabalho pedagógico com esses alunos deve procurar vias alternativas para a sua aprendizagem.

No entanto, a professora Larissa relata sobre as escolas que não possuem adaptação para receber todas as crianças de seis anos e, especificamente, aquelas com deficiência, tendo em vista que a inclusão desses alunos exige políticas públicas adequadas, as quais devem ser formuladas e/ou implementadas pelo poder público local.

A professora Larissa demonstra também em sua fala que se sente despreparada para atender esse alunado e destaca a necessidade de formação continuada para tal, ao se referir aos conhecimentos oriundos de sua formação em nível de pós-graduação lato sensu.

Entretanto, muitas professoras disseram que se envolvem em formação continuada ofertada pelo Município de Vitória e relataram utilizar diferentes teorias a fim de explicar ou dar base para sua prática. Contudo, vimos que o ecletismo teórico não era bem-visto por Vigotski (2003): "Beber da água" de diversificadas teorias para justificar ou dar base para a prática não colabora; pelo contrário, acaba por eliminar as diferenças e as contradições que expressam as incongruências da realidade, culminando em um amontoado de ideias sem fundamento, afastando-se da realidade concreta.

Chegamos à conclusão de que o docente precisa de uma formação sólida e teórica. É fundamental que ela seja baseada em profissionais mediadores, investigadores e conhecedores do processo de apropriação do conhecimento. As brincadeiras, junto aos temas voltados para a infância, devem ter maior espaço entre os professores alfabetizadores de crianças com seis anos do Ensino Fundamental. Algumas docentes citaram, como base de sua formação, autores como Vigotski, Emília Ferreiro, Ana Teberosky e Piaget. Outras não se lembravam de mais de autores das bases teórico-metodológicas estudadas, evidenciando a necessidade desse aprofundamento teórico-metodológico.

[...] alfabetização, a gente aprende todos os dias, no início foi muito difícil, você aprende na Faculdade, porque depois que a gente sai, fazer essa ponte o teórico com a prática, você percebe que muito que se falou lá você coloca em prática, mas mesmo assim, [...] consigo vivenciar de alguns autores: Piaget, Emília Ferreiro, Ana Teberosky, percebo muito isso quando eles começam a ler e escrever [...] (PROFESSORA LARISSA. TRANSCRIÇÃO DA ENTREVISTA).

Eu falo assim da minha, a busca de como eu iniciei, minha graduação, minha pós, psico, e também, a Ana Teberosky, Piaget e Vigotski, minha base teórica me ajudou muito, principalmente a Ana Teberosky, hoje eu não sei quais autores mais atuais, mas o que fez minha base foi a Ana Teberosky, a Emília Ferreiro, Piaget e o Vigotski, então a gente sempre trilhou buscar esses caminhos desses teóricos. Vigotski também que é proposta da Prefeitura (PROFESSORA LARISSA. TRANSCRIÇÃO DA ENTREVISTA).

Nessa perspectiva, nos excertos da entrevista da professora Larissa, observa-se o por uma formação sólida dos professores com base no domínio das fundamentações teóricas. 


\section{As concepções de professoras alfabetizadoras de alunos de primeiro ano acerca do processo de alfabetização}

As concepções das professoras alfabetizadoras de crianças do primeiro ano acerca do processo de alfabetização, constituíram-se com um eixo que colabora com as perspectivas da pesquisa no sentido de exprimir, a partir dos conhecimentos e vivências, como têm sido elaborados os conceitos que, de acordo com a nossa visão, são fundamentais para o entendimento ideológico que ampara as práticas desenvolvidas com as crianças com deficiência. Podemos verificar, nos excertos a seguir, as falas das educadoras em resposta às suas concepções sobre o processo de alfabetização:

[...] alfabetização é a base de todo aprendizado, tudo tem que ser divertido, ainda mais essa questão nossa que as crianças chegam com seis aninhos, a gente não pode esquecer daquela parte lúdica de aprender brincando (PROFESSORA BÁRBARA. TRANSCRIÇÃO DA ENTREVISTA).

[...] é algo que se constrói no dia a dia, você aproveita muito do que o aluno traz, não é estático, é movimento (PROFESSORA LARISSA. TRANSCRIÇÃO DA ENTREVISTA).

As docentes mostram tratar o processo de alfabetização como algo prazeroso indicando uma visão romantizada do processo e da criança. Além de considerá-la dentro de uma perspectiva organicista que exige vencer etapas.

[...] alfabetização, melhorou, antigamente as coisas eram decoradas, quadro, giz b com a ba, até eu já estava enjoada, hoje, você trabalha mais com música, poesia e jogos você tem mais recursos [...] (PROFESSORA BRUNELA. TRANSCRIÇÃO DA ENTREVISTA).

[...] cada criança tem o seu tempo, a gente já discutia isso que esse processo começa na educação infantil e perdura o primeiro ciclo todo [...] (PROFESSORA KARLA. TRANSCRIÇÃO DA ENTREVISTA).

A partir das falas de algumas professoras, observamos que a concepção de alfabetização pelo método tradicional é ainda latente nas escolas de ensino regular. Constatamos que temas como a história do sujeito, o lugar da brincadeira, as concepções de infância, a alfabetização, a aprendizagem e o desenvolvimento das crianças de seis anos de idade foram recorrentes, aparecendo, na maioria das vezes, ainda pouco aprofundados entre as docentes. Podemos inferir, em algumas falas, que Brunela, entre outras professoras, corrobora essa afirmação quando trabalha com música, poesia, arte e jogos com os alunos em suas aulas. Ressaltamos a nossa preocupação em torno desse grupo temático. Por outro lado, observamos, também, na fala da professora Larissa, a valorização do que o aluno traz do seu meio, enriquecendo, na escola, a sua visão na relação com os outros. Ela acrescenta também que o processo de alfabetização é a busca incessante, ou melhor, algo que se constrói no cotidiano.

Grando (2011), em seu estudo, nos ajuda a analisar a fala de Brunela, sobretudo quando ele apresenta uma reflexão em torno do tema da ludicidade e mostra as questões essenciais referentes às práticas de letramento que foram apresentadas pelas docentes e que se relacionam à construção de novas aprendizagens a partir do que já sabem, referindo-se também ao uso da escrita e da leitura e a importância de impulsionar práticas de letramento que sejam lúdicas no respeito às especificidades dos estudantes de 5 e 6 anos. 
Outrossim, percebemos também que a professora Karla, apesar de não ter enunciado diretamente, deixou indícios na sua fala de que uma criança precisa de um tempo maior, passando a ideia de que é necessário haver ações programadas para alfabetizar. Dessa maneira, notamos durante a entrevista que a prática de planejamento está muito latente nas escolas, isto é, muitas professoras consideram fundamental esse tempo, visto que muitas docentes se dedicam em pensar atividades diversificadas, utilizando estratégias e recursos pedagógicos em busca de potencializar as suas aulas, objetivando o desenvolvimento dos alunos.

Em outro momento da entrevista, a professora Regina falou que ainda utiliza o método tradicional em suas aulas. No seguinte excerto podemos observar.

[...] Do mesmo jeito que eu alfabetizo os outros, eu sou aquela professora tradicional, [...] eu confio no que eu faço, eu ainda trabalho com o método tradicional, sento, conto história, o aluno também participa. O foco maior é o tradicional, o silábico, não é, o sistema silábico, não sei como seria, eu falo o ba, be, bi, bo, bu. Risos. Família silábica. Depois você coloca as palavras certas, né, você vê um modo melhor de escrever [...] (PROFESSORA: REGINA. TRANSCRIÇÃO DA ENTREVISTA).

A professora relata que gosta e confia no método tradicional para alfabetizar os alunos. Ademais, o método tradicional de alfabetização é centralizado no professor, que tem a função de verificar se o aluno está seguindo tudo aquilo que Ihe foi solicitado.

O método tradicional de alfabetização intenciona desenvolver as habilidades essenciais que a criança deve ter para tornar-se um leitor habilidoso. Por conseguinte, só a presença dessas habilidades não garante sua utilização em tarefas mais complexas, como a leitura de um livro, a escrita de um poema ou mesmo a execução correta de receitas culinárias, entre outros. O contexto social que incentiva o interesse em aprender, independentemente da educação formal, é a chave para o uso dessas habilidades em qualquer atividade do ser humano, de modo especial as que envolvem a leitura e a escrita.

Oliveira (2008) desenvolveu um estudo mostrando em seus resultados indícios de que o contexto em que acontece a construção da hegemonia do construtivismo, pelas políticas da educação, colabora a fim de reproduzir a lógica que guia a organização do trabalho em educação, dissociando teorias e práticas. Os dados alcançados pela autora mostram indícios da convivência de ações e práticas variadas no ensino dessas docentes, tanto as reconhecidas com as proposições construtivistas como as reconhecidas com as proposições tradicionais. Espírito Santo (2010) percebeu falhas na formação do professor alfabetizador, concluindo que é possível superar esses problemas de formação na aproximação dos saberes teóricos com os saberes da prática. Nessa direção, vemos a necessidade da formação em ação e de estudos que trabalhem as questões metodológicas. Não é possível refletir os problemas da prática longe dela.

\section{As práticas pedagógicas das professoras alfabetizadoras: uma análise do processo de alfabetização na sala de ensino regular}

Achamos importante explicar como se configura o trabalho do professor alfabetizador que atua no Ensino Fundamental no Município de Vitória, por isso destacamos as práticas pedagógicas das professoras alfabetizadoras. Notamos, durante a entrevista, que as profissionais desenvolvem o seu trabalho como professora de sala regular no processo de alfabetização com o aluno de seis anos. Buscamos também saber, por meio de entrevista, o que elas consideram necessário ao aprendizado da criança no primeiro ano do Ensino Fundamental. As professoras afirmam que é necessário ao aprendizado 
[...] saber ler, interpretar e escrever, estudando de forma interdisciplinar, porque no segundo ano já vêm os conteúdos que a criança tem que dar conta (PROFESSORA ROSELY. TRANSCRIÇÃO DA ENTREVISTA).

[...] agora são três anos para alfabetizar, mas cada dia os meninos tão vindo mais imaturos pra EMEF [...] no CMEI, mesmo com todo o lúdico, eles vinham bem mais preparados, eu tô sentindo que eles estão com muita dificuldade. Ano passado, eu tinha uma turma, mas uma época assim, eu já tinha mais de dez lendo e agora eu tô com cinco, seis mais ou menos (PROFESSORA MARCELA. TRANSCRIÇÃO DA ENTREVISTA).

A partir dos dados, notamos que a professora entende que as crianças de seis anos estão chegando despreparadas ao primeiro ano de Ensino Fundamental. Porém, compreendemos que as atividades na Educação Infantil apresentam as suas especificidades próprias relacionadas ao desenvolvimento cognitivo e social da criança pequena, que se distanciam da preparação para o Ensino Fundamental.

O planejamento escolar deveria reconhecer as especificidades de cada etapa que é única para o desenvolvimento infantil. O espaço da educação infantil permite à criança uma liberdade com o lúdico, com a imaginação, com a criatividade e principalmente com as brincadeiras. No $1^{\circ}$ ano do ensino fundamental tais aspectos tornam-se mais distantes, tendo o predomínio da leitura e escrita como foco principal. No entanto, a aprendizagem poderá acontecer na situação da brincadeira pois assim a criança estará aberta a criar novos conceitos. Esse pensamento vai ao encontro do relato da professora Bárbara quando diz que o trabalho de alfabetização do professor tem que ser divertido. Assim, ela explica que

[...] alfabetizar é a base de todo aprendizado, tem que ser uma base bem sólida, [...] tudo tem que ser divertido, ainda mais essa questão nossa que as crianças chegam com seis aninhos, a gente não pode esquecer daquela parte lúdica [...] (PROFESSORA BÁRBARA, TRANSCRIÇÃO DA ENTREVISTA).

Cabe destacar a importância dos jogos, das rodas de leitura, dos momentos de produção e revisão de textos coletivos, assim como de atividades sistematizadas e reflexivas que ajudem os alunos a aprofundarem seus conhecimentos linguísticos.

Observa-se que a professora Bárbara, durante a entrevista, destaca a importância da brincadeira, isto é, dos momentos de interação com o meio como um elemento importante para o processo de desenvolvimento da leitura e da escrita. No entanto, conseguimos inferir, nas falas das professoras, que elas citam o método tradicional e os conteúdos disciplinares como uma questão relevante nesse momento. Nessa direção, Vygotsky (1987) alerta para o fato de que, em muitos casos, a aprendizagem da leitura e da escrita converte-se em uma tarefa mecânica e sem sentido para as crianças. A partir das entrevistas, notamos que as práticas pedagógicas envolvem a brincadeira, os jogos, as concepções de infância, a alfabetização, a aprendizagem e o desenvolvimento das crianças de seis anos de idade, mas apareceram como assuntos pouco aprofundados entre elas. 


\section{0 processo de alfabetização da criança público-alvo da educação especial: 0 que dizem as professoras alfabetizadoras?}

Nesse eixo de discussão, buscamos entender o processo de alfabetização da criança público-alvo da educação especial. Notamos que as professoras entendem a alfabetização da criança que apresenta DI como uma prática limitada, difícil e que requer muitos estudos. Em conversa com algumas docentes discutimos o trabalho realizado na sala de aula comum com a criança com deficiência intelectual, a organização desse trabalho, os entraves e as possibilidades de aprendizagem construídas nesse espaço.

Na faculdade, ela nos dá uma pincelada, e é direcionado ao Braille e ao surdo, mas a deficiência intelectual é falada na parte da psicologia infantil, mas o básico não te dá, não, temos que buscar, você chega na sala de aula e observa que aquela criança tem uma deficiência intelectual, [...] a gente não tem conhecimento de todas as deficiências. Ele não te dá base para atender a essas crianças, na prática, não, [...] só o dia a dia para te dar essa competência (PROFESSORA ROŞELY. TRANSCRIÇÃ̃ DA ENTREVISTA).

De acordo com a professora, os estudos direcionados para o processo de inclusão durante a formação inicial estão relacionados aos estudos de Psicologia ou de áreas da surdez e da cegueira. A docente sinaliza a necessidade da formação continuada dos professores, pois consideram os conhecimentos da formação inicial insuficientes para trabalhar com as crianças público-alvo da educação especial.

Podemos problematizar a formação desse professor, pois as Diretrizes Curriculares Nacionais Para o Curso de Pedagogia, segundo o Parecer CNE/CP n 5, de 13 de novembro de 2005, orientam que o perfil do graduado em Pedagogia necessita, entre outros aspectos, "[...] demonstrar consciência da diversidade, respeitando as diferenças de natureza, [...] necessidades especiais [...]" (CONSELHO NACIONAL DE EDUCAÇÃO, 2006), como também questionar o conteúdo do Projeto Pedagógico dos Cursos de Pedagogia.

Acerca da necessidade de formar o perfil pretendido pelo órgão oficial, constatamos durante o período de desenvolvimento da pesquisa que existe uma lacuna entre as orientações de documentos que compõem as políticas e a compreensão da maioria das participantes, pois a realidade vivida por elas nas escolas não condiz com a legislação, mesmo que reconheçam a importância da inclusão escolar. Vejamos, então:

[...] difícil trabalhar com os ditos normais que a gente não sabe o que é normal e sem deficiência, já tem a sua especificidade, imagine o aluno, não tem, eles não são contemplados, acredito se fosse trabalhar no lugar dele numa hora deles, eles teriam mais vantagens, o professor se desdobra, mas o aluno é jogado, não pelo professor, mas pelo sistema, não acho que ele deveria voltar, porque eu não sei a realidade de lá. Acho que ele deveria ser trabalhado individual, agora se o sistema, não quer arcar com essas despesas, sinto muito por ele, eu não sei porque eu acredito que na APAE trabalhava assim, porque eles têm que se integrar, mas tem que ser num outro espaço, é porque ele também tira o direito da outra criança de aprender (PROFESSORA REGINA. TRANSCRIÇÃO DA ENTREVISTA).

Verificamos que a professora Regina sugere que os alunos com DI estudem individualmente em um outro espaço fora da escola. Tal sugestão vai de encontro ao que determina a legislação quanto à obrigatoriedade em acolher e matricular todos os alunos, independentemente de suas necessidades ou diferenças. Em vista disso, é importante ressaltar o trabalho do professor como mediador no processo de ensino aprendizagem dessas crianças com o apoio de recursos e profissionais especializados. 
No entanto, o que observamos nas salas de aula é que, embora o trabalho em grupo possa ser produtivo e desafiador, propiciar trocas dialógicas e de informações e promover uma construção conjunta e um conhecimento partilhado, ele não é realizado quando se trata do aluno incluído (DAINÊZ; MONTEIRO; PADILHA, 2008). Essa forma de direcionar a prática pedagógica, de acordo com a perspectiva histórico-cultural, limita o desenvolvimento de processos compensatórios, já que os alunos não experimentam a cooperação e os desafios acadêmicos com outras pessoas.

Evidenciamos a categoria formação, que perpassa e problematiza os eixos temáticos discutidos nessa pesquisa. Essa categoria evidencia aspectos do processo formativo das professoras alfabetizadoras, além de mostrar aspectos positivos e as lacunas da formação continuada ofertada pelo município.

Quanto ao processo formativo, o ecletismo no seu referencial teórico permite as professoras alfabetizadoras uma confluência de métodos completamente diferentes, configura a insuficiência metodológica de princípios e o ecletismo de um sistema ainda carente. Esse ecletismo teórico, não era bem visto por Vigotski, pois "Beber da água" de diversificadas teorias para justificar ou dar base para a prática não colabora; pelo contrário, acaba por eliminar as diferenças e as contradições que expressam as incongruências da realidade, culminando em um amontoado de ideias sem fundamento, afastando-se da realidade concreta.

As discussões revelam que a formação docente deste Município, preocupa-se com a formação dos professores que atuam no processo de alfabetização. No entanto, o que ocorre é que essas formações não tem privilegiado a criança com Deficiência Intelectual e sua alfabetização.

\section{Considerações finais}

Este estudo nos deu condições de conhecer os conhecimentos, as concepções e as práticas das professoras de alfabetizadoras que atuam com crianças de seis anos com DI no Município de Vitória. Em seu percurso, este texto mostrou que as professoras seguem vários métodos, confirmando a estreiteza metodológica de convicções e o ecletismo de um sistema falho. Os professores precisam ser bem-preparados durante o seu processo de formação, em que ainda percebemos lacunas.

A maioria das professoras participantes da pesquisa demonstraram distanciamento dos estudos teóricos da época em que fizeram a graduação, privilegiando os conhecimentos práticos referentes à alfabetização. A pesquisa indicou ainda que muitas das professoras se apoiavam em várias teorias para a organização do processo de alfabetização, evidenciando, pouco aprofundamento na apropriação do conhecimento e, também, pouco direcionamento da intencionalidade e sistematização de sua mediação pedagógica para os alunos.

Um ponto de destaque que julgamos importante a partir da categoria formação foi o ecletismo dos conhecimentos, já que alguns professores se recordaram, embora de modo fragmentado, de teóricos presentes nos estudos de alfabetização, mas que não possuem bases epistemológicas em comum e/ou que não se associam. Pelo contrário, a associação das teorias anula as diferentes perspectivas que cada um possui de um mesmo fato e os reduz, descaracterizando-os. Para a superação dessa situação a formação dos profissionais da educação caracteriza-se como elemento fundamental.

Todos os professores devem saber atuar com o estudante público-alvo da educação especial, para intervir face às diferenças entre os alunos atendidos, a fim de que transformações no sistema de ensino venham a beneficiar todo e qualquer sujeito, considerando a especificidade do ser humano e não mais as suas limitações. Entendemos que o professor deve promover a apropriação de conceitos científicos, independentemente de trabalharem com sujeitos "normais" ou não. 
Além do mais, o professor deve ter uma dimensão ampla de alfabetização, devendo saber planejar e conduzir de forma segura o processo. É preciso olhar com outros olhos para a alfabetização, a partir da formação de profissionais bem preparados, os quais observem a necessidade de seus alunos, dando-Ihes ferramentas para poderem exercer dignamente a sua cidadania.

Por fim, notamos que as professoras alfabetizadoras que mostraram proximidade com a teoria Histórico-Cultural, especificamente as que trabalham com a educação especial e alunos com DI, revelaram mais segurança e mais potência em seu trabalho. Nessa direção, percebemos que elas trabalham com a intenção de facilitar a construção do conhecimento, considerando as diferenças individuais, como as habilidades, os ritmos e a capacidades para lidar com o processo de alfabetização de aluno com Deficiência Intelectual.

\section{Referências}

BAPTISTA, C. R. Ação pedagógica e educação especial: a sala de recursos como prioridade na oferta de serviços especializados. Rev. Bras., Marília, v. 17, p. 59-76, maio/ago., 2011. Edição especial.

CONSELHO NACIONAL DE EDUCAÇÃO (Brasil). Parecer CNE/CP n 5, de 13 de novembro de 2005, reexaminado pelo Parecer $\mathrm{n}^{\circ}$ 3, de 21 de fevereiro de 2006, Diário Oficial da União, Brasília, 2006. Disponível em: <http:// portal.mec.gov.br/cne/arquivos/pdf/pcp05_05.pdf>. Acesso em: 17 jul. 2017.

DAINÊZ, D.; MONTEIRO, Maria I. B.; PADILHA, A. M. L. Compensação e suas implicações educacionais: refletindo sobre a inclusão escolar de crianças com necessidades educativas especiais. In: SEMINÁRIO DE PESQUISA EM EDUCAÇÃO ESPECIAL: CONHECIMENTO E MARGENS, 4., 2008, São Paulo. Anais... São Paulo: Unimep, 2008. Disponível em: <www.unimep.br/ mbmontei/iv-seminarionacional-pesquisa-ed-especial-2008. pdf>. Acesso em: 20 jul. 2017.

DENARI, F. Um (novo) olhar sobre a formação do professor de educação especial: da segregação à inclusão. In: RODRIGUES, D. (Org.). Inclusão e educação: doze olhares sobre a educação inclusiva. São Paulo: Summus, 2006. p.35-36.

ESPÍRITO SANTO, E. B. Dos saberes teóricos aos saberes da ação: a construção de concepções e práticas alfabetizadoras. 2010. 191 f. Dissertação (Mestrado em Educação) - Programa de Pós-Graduação em Educação: Conhecimento e Inclusão Social, Universidade Federal de Minas Gerais, 2010.

GÓES, M. C. R. As contribuições da abordagem histórico-cultural para a pesquisa em educação especial. In: BAPTISTA, C. R.; CAIADO, K. R. M., JESUS, D. M. Educação Especial: diálogo e pluralidade. Porto Alegre: Mediação, 2008.

GONTIJO, C. M. M. A escrita infantil. São Paulo: Cortez, 2008.

Alfabetização: políticas mundiais e movimentos nacionais. Educação Contemporânea. Campinas: Autores Associados, 2014.

GLAT, R.; SANTOS; M. P.; SOUSA. L. P. F.; XAVIER, K. R. Formação de professores na educação inclusiva: diretrizes políticas e resultados de pesquisas. In: ENCONTRO NACIONAL DE DIDÁTICA E PRÁTICA DE ENSINO (ENDIPE), 13., 2006, Recife. Anais... Recife, 2006.

GRANDO, K. B. Práticas de letramento no Ensino Fundamental: vozes das professoras. 2011. 147 f. Dissertação (Mestrado em Educação) - Programa de Pós-Graduação em Educação, Pontifícia Universidade Católica do Rio Grande do Sul, Porto Alegre, 2011.

JESUS, D. M. Políticas de inclusão: para iniciar o diálogo. In: BAPTISTA, C. R.; JESUS, D. M. (Org.). Avanços em políticas de inclusão: o contexto da educação especial no Brasil e em outros países. Porto Alegre: Mediação/ CDV/FACITEC, 2009, p. 5-27. 
LIBÂNEO, J. C.; FREITAS, R A. M. M. Vygotsky, Leontiev, Davydov: três aportes teóricos para a teoria históricocultural e suas contribuições para a didática. In: CONGRESSO BRASILEIRO DE HISTÓRIA DA EDUCAÇÃO, 4., 2006, Goiânia. Anais... Goiânia: Sociedade Brasileira de História da Educação, 2006. Disponível em: <http:// www. sbhe.org. br/novo/congressos/cbhe4/individuais-coautorais/eixo03/Jose\%20Carlos\%20Libaneo\%20e\%20 Raquel\%20A.\%20M.\%20da\%20M.\%20Freitas\%20-\%20Texto.pdf>. Acesso em: 15 mar. 2017.

NETO J. P. Introdução ao estudo do método de Marx Categorias Filosofia, História Geral, Serviço Social. Etiquetas: Coleção de Bolso, Expressão Popular, 2011.

OLIVEIRA, T. F. M. Conhecimentos manifestos pelos professores para o ensino na alfabetização escolar. 2008. 212 f. Tese (Doutorado em Educação) - Pontifícia Universidade Católica de São Paulo, São Paulo, 2008.

PINTO, R. M. et al. Fracasso escolar no sexto ano do ensino fundamental: causas e consequências. II CONEDU CONGRESSO NACIONAL DE EDUCAÇÃO, 2., 2015, Caxias. Anais... Caxias: Instituto Federal de Educação, Ciência e Tecnologia do Maranhão, Campus Caxias, 2015.

PRIETO, R. G. et al. Política de educação especial no Brasil: evolução das garantias legais. In: SEMINÁRIO CAPIXABA DE EDUCAÇÃO INCLUSIVA, 11., 2008, Vitória. Anais... Vitória: Programa de Pós-Graduação em Educação/UFES, 2008.

SILVA, A. P. M.; ARRUDA, A. L. M. M. O papel do professor diante da inclusão escolar. Revista Eletrônica Saberes da Educação, v. 5, n. 1, 2014.

VELTRONE, A. A.; MENDES, E. A formação docente na perspectiva da inclusão: diretrizes e desafios na formação inicial e continuada de professores para a inclusão escolar. In: CONGRESSO ESTADUAL PAULISTA SOBRE FORMAÇÃO DE EDUCADORES, 9., 2007, São Paulo. Anais... São Paulo: Pró-Reitoria de Graduação/ UNESP, 2007. Disponível em: <www.unesp.br/prograd/ixcepfe/Arquivos\%202007/5eixo.pdf>. Acesso em: 17 jan. 2018.

VITÓRIA. Secretaria Municipal de Gestão Estratégica. Relatório da Gestão Municipal. Vitória em foco. Vitória, 2012.

Secretaria Municipal de Educação. Ciclo Inicial de Aprendizagem. Documento orientador. Vitória, 2011.

VIGOTSKI, L. S. Artículo de introdución sobre la labor creadora de L. S. VIGOTSKI. In: VIGOTSKI, L. S. Obras escogidas I: problemas teóricos y metodológicos de la psicologia. 2. ed. Tradução de José Maria Bravo. Madrid: Visor Distribuciones, 1997. p. 419-150.

VIGOTSKI, L. S. Criação e imaginação na infância. São Paulo: Ática, 2003.

VIGOTSKY, L. S. El arte y la imaginación en la infancia. Madrid: Akal, 1987.

A construção do pensamento e da linguagem. São Paulo: Martins Fontes, 2000

Recebido em: 27/01/2021

Aceito em: 20/09/2021 